Supporting Information

\title{
Stereoselective Synthesis of New Conformationally Restricted Analogs of a Potent CGRP Receptor Antagonist
}

Dmitry Zuev, Jodi A. Michne, Hong Huang, Brett R. Beno, Dedong Wu, Qi Gao, John R. Torrente, Cen Xu, Charles M. Conway, John E. Macor and Gene M. Dubowchik

Bristol-Myers Squibb Pharmaceutical Research Institute, P.O. Box 5100, Wallingford, CT 06492 
Materials and Methods. Reactions were carried out in oven or flame-dried glassware under an argon atmosphere, unless otherwise noted. All solvents were reagent grade. Lithium diisopropylamide was purchased from Aldrich. Reactions were magnetically stirred and monitored by thin-layer chromatography (TLC) with silica gel $60 \mathrm{~F}_{254} \mathrm{EMD}$ precoated plates or by a liquid chromatography-mass spectrometry (LCMS) method under the following conditions - column PHENOMENEX-LUNA 4.6×50 mm; solvent A - methanol (10\%) - water $(90 \%)$ TFA (0.1\%); solvent B - methanol $(90 \%)$ - water $(10 \%)$ - TFA $(0.1 \%)$; starting $\% \mathrm{~B}-0$, final \%B -100 ; flow rate $-4 \mathrm{~mL} / \mathrm{min}$, gradient time $-2 \mathrm{~min}$, end time -3 min. Yields refer to chromatographically and spectroscopically pure compounds, unless otherwise stated. Proton NMR spectra were recorded on a Bruker AMX400 and AMX-500 spectrometers. Chemical shifts are reported relative to chloroform ( $\delta 7.26)$, benzene $(\delta 7.16)$ and methanol $(\delta 3.34)$.

\section{Experimental Procedures.}

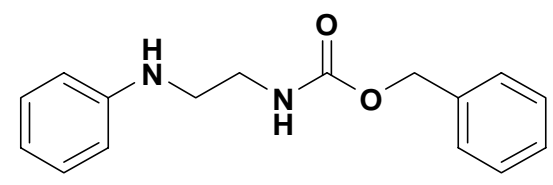

Benzyl 2-(phenylamino)ethylcarbamate $6 a$. To a solution of $\mathrm{N}-(2-$ aminoethyl)benzenamine $(1.92 \mathrm{~mL}, 0.015 \mathrm{~mol})$ in dichloromethane $(50 \mathrm{~mL})$ was added triethylamine $(2.79 \mathrm{~mL}, 0.020 \mathrm{~mol})$ and benzyl chloroformate $(2.11 \mathrm{~mL}$, $0.015 \mathrm{~mol}$ ). The reaction mixture was stirred at room temperature for $24 \mathrm{~h}$. Water 
was added. The organic layer was separated and the aqueous layer was extracted with dichloromethane. The combined organic layers were dried over anhydrous sodium sulfate, filtered and concentrated in vacuum. The crude product was purified by column chromatography on silica gel (hexanes ethylacetate $-4: 1$ to $1: 1)$ to provide the title compound ( $1.90 \mathrm{~g}, 47 \%$ yield) as colorless oil. ${ }^{1} \mathrm{H}$ NMR $(500 \mathrm{MHz}, \mathrm{MeOH} d 4) \delta 7.36(\mathrm{~s}, 5 \mathrm{H}), 7.35-7.29(\mathrm{~m}, 1 \mathrm{H})$, 7.11 (t, $J=7.5 \mathrm{~Hz}, 1 \mathrm{H}), 6.66-6.61(\mathrm{~m}, 3 \mathrm{H}), 5.09(\mathrm{~s}, 2 \mathrm{H}), 3.33(\mathrm{t}, J=6.0 \mathrm{~Hz}, 2 \mathrm{H})$, $3.22(\mathrm{t}, J=6.0 \mathrm{~Hz}, 2 \mathrm{H})$. MS (ESI) calculated $\mathrm{m} / \mathrm{z} 271.15[\mathrm{M}+\mathrm{H}]^{+}$, found $\mathrm{m} / \mathrm{z}$ $271.11[\mathrm{M}+\mathrm{H}]^{+}$.

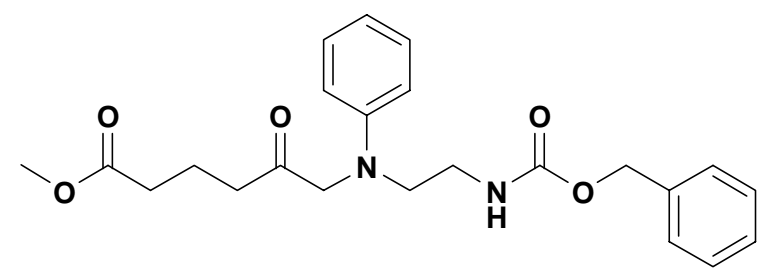

\section{Methyl 6-((2-(benzyloxycarbonyl)ethyl)(phenyl)amino)-5-oxohexanoate 7a.}

To a solution of benzyl 2-(phenylamino)ethylcarbamate $6 \mathrm{a}(1.880 \mathrm{~g}, 6.954 \mathrm{mmol})$ and methyl 6-bromo-5-oxohexanoate $(4.653 \mathrm{~g}, 20.862 \mathrm{mmol})$ in acetone $(50 \mathrm{~mL})$ were added potassium carbonate $(0.967 \mathrm{~g}, 7.000 \mathrm{mmol})$ and potassium iodide $(1.162 \mathrm{~g}, 7.000 \mathrm{mmol})$. The reaction mixture was stirred at room temperature overnight. Acetone was removed under reduced pressure and the residue was partitioned between water and ethylacetate. The organic layer was separated and the aqueous layer was extracted with ethylacetate. The combined organic extracts were dried over anhydrous sodium sulfate, filtered and concentrated in 
vacuum. The crude product was purified by column chromatography on silica gel (hexanes - ethylacetate $-2: 1$ to $1: 4)$ to provide the title compound $(2.581 \mathrm{~g}, 90 \%$ yield) as light brown oil. ${ }^{1} \mathrm{H} \mathrm{NMR}(500 \mathrm{MHz}, \mathrm{MeOH}$ d4) $\delta 7.34(\mathrm{~s}, 5 \mathrm{H}), 7.34-7.30$ (m, 1H), $7.15(\mathrm{t}, J=7.5 \mathrm{~Hz}, 1 \mathrm{H}), 6.66(\mathrm{t}, J=7.5 \mathrm{~Hz}, 1 \mathrm{H}), 6.62(\mathrm{~d}, J=8.5 \mathrm{~Hz}, 2 \mathrm{H})$, $5.08(\mathrm{~s}, 2 \mathrm{H}), 4.86(\mathrm{~s}, 2 \mathrm{H}), 3.64(\mathrm{~s}, 3 \mathrm{H}), 3.50(\mathrm{t}, J=6.5 \mathrm{~Hz}, 2 \mathrm{H}), 3.32(\mathrm{t}, J=6.5$ $\mathrm{Hz}, 2 \mathrm{H}), 2.55(\mathrm{t}, J=7.0 \mathrm{~Hz}, 2 \mathrm{H}), 2.33(\mathrm{t}, J=7.5 \mathrm{~Hz}, 2 \mathrm{H}), 1.85(\mathrm{t}, J=7.5 \mathrm{~Hz}, 2 \mathrm{H})$. MS (ESI) calculated $m / z 435.19[\mathrm{M}+\mathrm{Na}]^{+}$, found $m / z 435.15[\mathrm{M}+\mathrm{Na}]^{+}$.

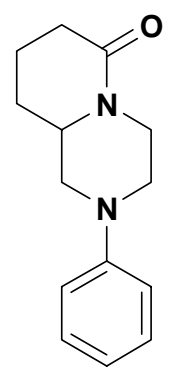

2-Phenyl-octahydropyrido[1,2-a]pyrazin-6-one (TFA salt) 3a: To a solution of methyl 6-((2-(benzyloxycarbonyl)ethyl)(phenyl)amino)-5-oxohexanoate 7a (3.800 $\mathrm{g}, 9.213 \mathrm{mmol})$ in ethanol $(25 \mathrm{~mL})$ was added 1,4-cyclohexadiene $(4.4 \mathrm{~mL}, 46.51$ $\mathrm{mmol}$ ) and $10 \%$ palladium on carbon $(1.24 \mathrm{~g})$. The reaction mixture was refluxed for $2 \mathrm{~min}$, cooled to room temperature and filtered through a short plug of celite. The filtrate was concentrated in vacuum to provide methyl 6-((2aminoethyl)(phenyl)amino)-5-oxohexanoate $(2.56 \mathrm{~g}, 100 \%)$ as brown oil. To a solution of 6-((2-aminoethyl)(phenyl)amino)-5-oxohexanoate $(67.4 \mathrm{mg}, 0.242$ $\mathrm{mmol})$ in methanol $(1.0 \mathrm{~mL})$ was added sodium cyanoborohydride $(76.0 \mathrm{mg}$, $1.210 \mathrm{mmol}$ ) at $0^{\circ} \mathrm{C}$, and the resulting solution was adjusted to $\mathrm{pH} 5$ by dropwise 
addition of $4 \mathrm{~N}$ hydrogen chloride in 1,4-dioxane. The reaction mixture was refluxed for $6 \mathrm{~h}$. The excess of sodium cyanoborohydride was destroyed by addition of $4 \mathrm{~N}$ hydrogen chloride in 1,4-dioxane at $0^{\circ} \mathrm{C}$ until bubbling stopped. The reaction mixture was carefully poured into an aqueous potassium carbonate solution and extracted with dichloromethane. The combined organic layers were dried over anhydrous sodium sulfate. Ensuing purification by reverse phase preparative HPLC (column - XTERRA 30×150 mm S5; injection volume - 2000 $\mu \mathrm{L}$, solvent A - methanol (10\%) - water $(90 \%)$ - TFA (0.1\%); solvent B methanol $(90 \%)$ - water (10\%) - TFA (0.1\%); flow rate - $25 \mathrm{~mL} / \mathrm{min}$; starting \%B -20 , final $\% B-80$; gradient time $-20 \mathrm{~min}$, stop time $-25 \mathrm{~min}$ ) provided the desired product as colorless oil (23.5 mg, 45\%). ${ }^{1} \mathrm{H}$ NMR $\left(400 \mathrm{MHz}, \mathrm{CDCl}_{3}\right) \delta$ 7.49-7.25 (m, 5H), $4.06(\mathrm{~m}, 1 \mathrm{H}), 3.75(\mathrm{~d}, J=10.4 \mathrm{~Hz}, 2 \mathrm{H}), 3.24(\mathrm{~m}, 2 \mathrm{H}), 2.99(\mathrm{t}, J$ $=11.6 \mathrm{~Hz}, 2 \mathrm{H}), 2.68-2.50(\mathrm{~m}, 1 \mathrm{H}), 2.50-2.35(\mathrm{~m}, 1 \mathrm{H}), 2.20-2.05(\mathrm{~m}, 1 \mathrm{H}), 2.00-$ $1.70(\mathrm{~m}, 2 \mathrm{H}), 1.60-1.45(\mathrm{~m}, 1 \mathrm{H}) . \mathrm{MS}(\mathrm{ESI})$ calculated $\mathrm{m} / \mathrm{z} 231.15[\mathrm{M}+\mathrm{H}]^{+}$, found $m / z 231.24[\mathrm{M}+\mathrm{H}]^{+}$.

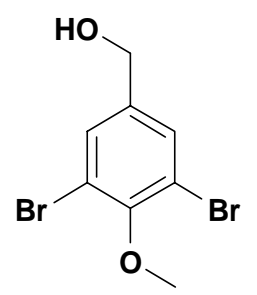

(3,5-Dibromo-4-methoxyphenyl)methanol: To a solution of 3,5-dibromo-4methoxybenzaldehyde $9(5.25 \mathrm{~g}, 17.86 \mathrm{mmol})$ in ethanol $(50 \mathrm{~mL})$ cooled to $0^{\circ} \mathrm{C}$ was added sodium borohydride $(0.68 \mathrm{~g}, 18.00 \mathrm{mmol})$. The reaction mixture was 
stirred at room temperature for $2 \mathrm{~h}$. Ethanol was evaporated in vacuum and the residue was partitioned between ethylacetate and water. The organic layer was separated and the aqueous layer was extracted with ethylacetate. The combined organic layers were dried over anhydrous sodium sulfate, filtered and concentrated in vacuum. The crude product was purified by column chromatography on silica gel (hexanes - ethylacetate $-6: 1$ to $3: 1$ ) to provide the title compound (5.29 g, 100\% yield) as colorless oil. ${ }^{1} \mathrm{H} \mathrm{NMR}\left(500 \mathrm{MHz}, \mathrm{CDCl}_{3}\right) \delta$ $7.46(\mathrm{~s}, 2 \mathrm{H}), 4.57(\mathrm{~s}, 2 \mathrm{H}), 3.84(\mathrm{~s}, 3 \mathrm{H}) . \mathrm{MS}(\mathrm{ESI})$ calculated $\mathrm{m} / \mathrm{z} 276.89[\mathrm{M}-\mathrm{OH}]^{+}$, found $m / z 276.99[\mathrm{M}-\mathrm{OH}]^{+}$.

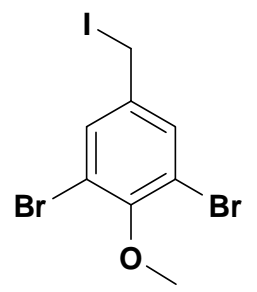

1,3-Dibromo-5-(iodomethyl)-2-methoxybenzene 10: To a solution of (3,5dibromo-4-methoxyphenyl)methanol (500 mg, $1.689 \mathrm{mmol})$ in 1,4-dioxane (3.5 $\mathrm{mL}$ ) cooled to $0^{\circ} \mathrm{C}$ were added boron trifluoride etherate $(0.32 \mathrm{~mL}, 2.534 \mathrm{mmol})$ and potassium iodide $(420.7 \mathrm{mg}, 2.534 \mathrm{~mol})$. The reaction mixture was stirred at room temperature for $8 \mathrm{~h}$. Cold water and ether were added. The organic layer was separated, and the aqueous layer was extracted with ether. The combined organic extracts were dried over anhydrous sodium sulfate, filtered and concentrated in vacuum at room temperature to provide the desired product 
(630.7 mg, 92\%) as white solid. ${ }^{1} \mathrm{H}$ NMR $(500 \mathrm{MHz}, \mathrm{MeOH}$ d4) $\delta 7.50(\mathrm{~s}, 2 \mathrm{H})$, $4.31(\mathrm{~s}, 2 \mathrm{H}), 3.87(\mathrm{~s}, 3 \mathrm{H})$.

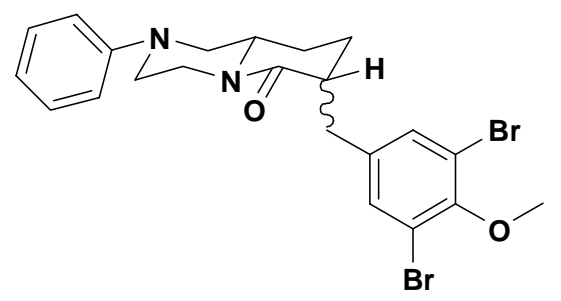

\section{7-(3,5-dibromo-4-methoxybenzyl)-2-phenyl-octahydropyrido[1,2-a]pyrazin-}

6-one 11a: To a 2.0M solution of lithium diisopropylamide in heptane - THF ethylbenzene $(0.98 \mathrm{~mL}, 1.969 \mathrm{mmol})$ cooled to $-78^{\circ} \mathrm{C}$ was added $\mathrm{THF}(0.5 \mathrm{~mL})$ and 2-phenyloctahydropyrido[1,2-a]pyrazin-6-one $3 a(412.2 \mathrm{mg}, 1.790 \mathrm{mmol})$ in THF $(1.5 \mathrm{~mL})$ via cannula. The resulting solution was stirred at $-78^{\circ} \mathrm{C}$ for $2 \mathrm{~h} 15$ min. A solution of 1,3-dibromo-5-(iodomethyl)-2-methoxybenzene 10 (799.1 mg, $1.969 \mathrm{mmol})$ in THF $(2.0 \mathrm{~mL})$ was cannulated, and the reaction mixture was warmed to $-20^{\circ} \mathrm{C}$ and stirred overnight, while allowing to warm to $+10^{\circ} \mathrm{C}$. Aqueous ammonium chloride and dichloromethane were added at $0^{\circ} \mathrm{C}$. The organic phase was separated and the aqueous phase was extracted with dichloromethane. The combined organic extracts were dried over anhydrous sodium sulfate, filtered and concentrated in vacuum. The crude product was purified by column chromatography on silica gel (hexanes - ethylacetate - 6:1 to 3:1) to provide the title product as two diastereomers. Diastereomer A (327.5 mg, 36\%, colorless oil): ${ }^{1} \mathrm{H}$ NMR $(500 \mathrm{MHz}, \mathrm{MeOH}$ d4) $\delta 7.48(\mathrm{~s}, 2 \mathrm{H}), 7.26(\mathrm{t}, J=7.0$ $\mathrm{Hz}, 2 \mathrm{H}), 7.00(\mathrm{~d}, J=8.0 \mathrm{~Hz}, 2 \mathrm{H}), 6.87(\mathrm{t}, J=7.5 \mathrm{~Hz}, 1 \mathrm{H}), 4.69(\mathrm{~m}, 1 \mathrm{H}), 3.85(\mathrm{~s}$, 
$3 \mathrm{H}), 3.71-3.64(\mathrm{~m}, 2 \mathrm{H}), 3.64-3.55(\mathrm{~m}, 1 \mathrm{H}), 3.25\left(\mathrm{dd}, J_{1}=14.0 \mathrm{~Hz}, J_{2}=4.5 \mathrm{~Hz}\right.$, 1H), $2.91(m, 1 H), 2.72-2.65(m, 2 H), 2.62-2.53(m, 1 H), 2.48(t, J=10.5 \mathrm{~Hz}, 1 \mathrm{H})$, 2.12-2.07 (m, 1H), 1.82-1.75 (m, 1H), 1.67-1.35 (m, 2H). MS (ESI) calculated $m / z$ $507.03[\mathrm{M}+\mathrm{H}]^{+}$, found $\mathrm{m} / \mathrm{z} 507.19[\mathrm{M}+\mathrm{H}]^{+}$. Diastereomer B $(282.0 \mathrm{mg}, 31 \%$, colorless oil): ${ }^{1} \mathrm{H}$ NMR (500 MHz, MeOH d4) $\delta 7.49(\mathrm{~s}, 2 \mathrm{H}), 7.26$ (t, $J=7.5 \mathrm{~Hz}$, 2H), $7.00(\mathrm{~d}, J=8.5 \mathrm{~Hz}, 2 \mathrm{H}), 6.88(\mathrm{t}, J=7.5 \mathrm{~Hz}, 1 \mathrm{H}), 4.69(\mathrm{~m}, 1 \mathrm{H}), 3.81(\mathrm{~s}, 3 \mathrm{H})$, 3.70-3.56 (m, 3H), $3.05\left(\mathrm{dd}, J_{1}=14.0 \mathrm{~Hz}, J_{2}=4.5 \mathrm{~Hz}, 1 \mathrm{H}\right), 2.92(\mathrm{~m}, 1 \mathrm{H}), 2.85$ (dd, $J_{1}=13.5 \mathrm{~Hz}, J_{2}=9.0 \mathrm{~Hz}, 1 \mathrm{H}$ ), $2.69-2.62(\mathrm{~m}, 2 \mathrm{H}), 2.43(\mathrm{t}, J=11.0 \mathrm{~Hz}, 1 \mathrm{H}$ ), 1.97-1.90 (m, $1 \mathrm{H}), 1.82-1.72(\mathrm{~m}, 1 \mathrm{H}), 1.70-1.58(\mathrm{~m}, 2 \mathrm{H}) . \mathrm{MS}(\mathrm{ESI})$ calculated $\mathrm{m} / \mathrm{z}$ $507.03[\mathrm{M}+\mathrm{H}]^{+}$, found $\mathrm{m} / \mathrm{z} 507.17[\mathrm{M}+\mathrm{H}]^{+}$.
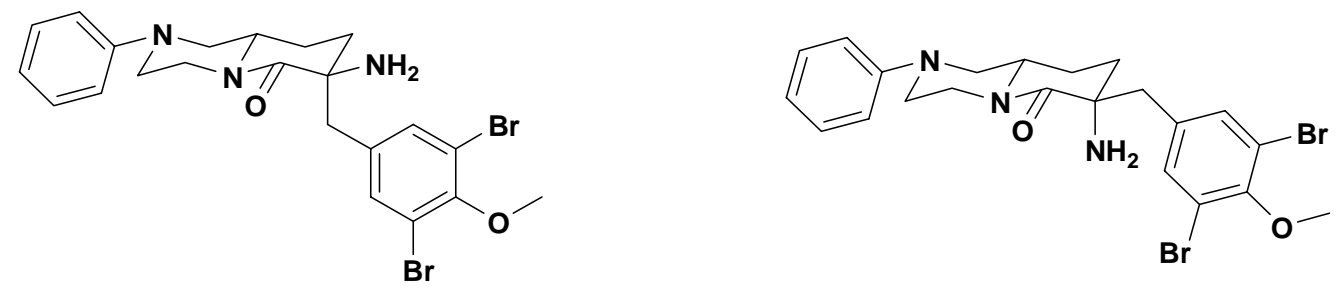

\section{7-(3,5-dibromo-4-methoxybenzyl)-7-amino-2-phenyl-octahydropyrido[1,2-}

a]pyrazin-6-one (double TFA salt) 13a and 14a: To a 2.0M solution of lithium diisopropylamide in heptane - THF - ethylbenzene $(0.43 \mathrm{~mL}, 0.866 \mathrm{mmol})$ cooled to $-78^{\circ} \mathrm{C}$ was added $\mathrm{THF}(0.5 \mathrm{~mL})$ and 7-(3,5-dibromo-4-methoxybenzyl)-2phenyl-octahydropyrido[1,2-a]pyrazin-6-one 11a (293.1 $\mathrm{mg}, 0.577 \mathrm{mmol})$ in THF $(1.5 \mathrm{~mL})$ via cannula. The resulting solution was stirred at $-78^{\circ} \mathrm{C}$ for $2 \mathrm{~h} 10 \mathrm{~min}$, then - warmed to $-20^{\circ} \mathrm{C}$. Propyl nitrate $(0.09 \mathrm{~mL}, 0.866 \mathrm{mmol})$ was added and the reaction mixture was allowed to warm to $+5^{\circ} \mathrm{C}$ over $3 \mathrm{~h}$. Aqueous ammonium 
chloride and dichloromethane were added at $0^{\circ} \mathrm{C}$. The organic phase was separated and the aqueous phase was extracted with dichloromethane. The combined organic extracts were dried over sodium sulfate and concentrated in vacuum to provide the crude product as a $5: 1$ mixture of diastereomers $(41 \%$ combined yield, as determined by LCMS). Concentrated aqueous solution of hydrogen chloride $(10 \mathrm{~mL})$ and 1,4-dioxane $(10 \mathrm{~mL})$ were added to dissolve the crude product. Zinc was added by small portions to the resulting solution until the conversion to the product was complete (control by LCMS). The solvent was concentrated in vacuum and the residue was purified by a reverse phase preparative HPLC (column - XTERRA 30×150 mm S5; injection volume - 2000 $\mu \mathrm{L}$, solvent A - methanol (10\%) - water $(90 \%)$ - TFA $(0.1 \%)$; solvent B methanol $(90 \%)$ - water (10\%) - TFA (0.1\%); flow rate $-25 \mathrm{~mL} / \mathrm{min}$; starting \%B -20 , final \%B -80 ; gradient time $-20 \mathrm{~min}$, stop time $-25 \mathrm{~min}$ ) to provide the title compound as two diastereomers. Trans-isomer 13a $(97.7 \mathrm{mg}, 55 \%$ yield, colorless semisolid) ${ }^{1} \mathrm{H}$ NMR (500 MHz, MeOH d4) $\delta 7.54(\mathrm{~s}, 2 \mathrm{H}), 7.27$ (t, $J=7.5$ $\mathrm{Hz}, 2 \mathrm{H}), 7.01(\mathrm{~d}, J=8.0 \mathrm{~Hz}, 2 \mathrm{H}), 6.90(\mathrm{t}, J=7.5 \mathrm{~Hz}, 1 \mathrm{H}), 4.66(\mathrm{~m}, 1 \mathrm{H}), 3.75(\mathrm{~m}$, 1H), $3.64\left(\mathrm{dd}, J_{1}=14.0 \mathrm{~Hz}, J_{2}=4.5 \mathrm{~Hz}, 1 \mathrm{H}\right), 3.40(\mathrm{~d}, J=14.0 \mathrm{~Hz}, 1 \mathrm{H}), 3.14(\mathrm{~d}, J$ $=14.5 \mathrm{~Hz}, 1 \mathrm{H}), 3.01(\mathrm{~m}, 1 \mathrm{H}), 2.82-2.70(\mathrm{~m}, 2 \mathrm{H}), 2.22-2.12(\mathrm{~m}, 2 \mathrm{H})$, 2.12-1.97 $(\mathrm{m}$, $2 \mathrm{H}), 1.70-1.57(\mathrm{~m}, 2 \mathrm{H})$. MS $(\mathrm{ESI})$ calculated $\mathrm{m} / \mathrm{z} 522.04[\mathrm{M}+\mathrm{H}]^{+}$, found $\mathrm{m} / \mathrm{z}$ $521.94[\mathrm{M}+\mathrm{H}]^{+}$. Cis-isomer 14a (19.5 mg, 11\% yield, colorless semisolid) ${ }^{1} \mathrm{H}$ NMR (500 MHz, MeOH d4) $\delta 7.55(\mathrm{~s}, 2 \mathrm{H}), 7.28(\mathrm{t}, J=7.5 \mathrm{~Hz}, 2 \mathrm{H}), 7.01$ (d, $J=$ $8.0 \mathrm{~Hz}, 2 \mathrm{H}), 6.91(\mathrm{t}, J=7.5 \mathrm{~Hz}, 1 \mathrm{H}), 4.58(\mathrm{~m}, 1 \mathrm{H}), 3.81(\mathrm{~s}, 3 \mathrm{H}), 3.75(\mathrm{~m}, 1 \mathrm{H})$, $3.66(\mathrm{~d}, J=12.0 \mathrm{~Hz}, 2 \mathrm{H}), 3.14(\mathrm{~d}, J=14.0 \mathrm{~Hz}, 1 \mathrm{H}), 3.00(\mathrm{~m}, 1 \mathrm{H}), 2.73(\mathrm{~m}, 1 \mathrm{H})$, 
2.28-2.16 (m, 2H), 2.13-2.00 (m, 2H), 1.73-1.58 (m, 1H), 1.42-1.23 (m, 1H). MS (ESI) calculated $m / z 522.04[\mathrm{M}+\mathrm{H}]^{+}$, found $m / z 521.94[\mathrm{M}+\mathrm{H}]^{+}$.

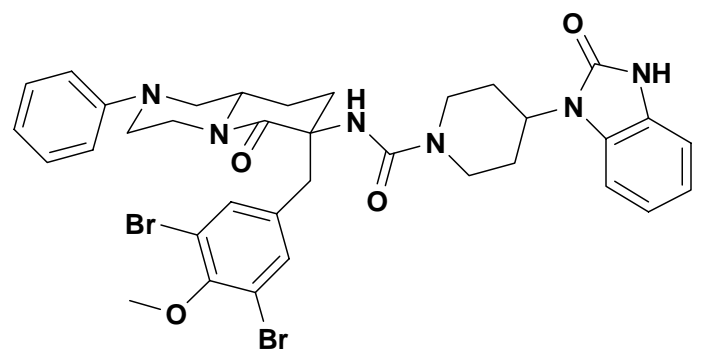

Trans- N-(7-(3,5-dibromo-4-methoxybenzyl)-6-oxo-2-phenyl-octahydro-1Hpyrido[1,2-a]pyrazin-7-yl)-4-(2-oxo-2,3-dihydrobenzo[d]imidazol-1yl)piperidine-1-carboxamide (TFA salt) 15a: To a suspension of trans- 7-(3,5dibromo-4-methoxybenzyl)-7-amino-2-phenyl-octahydropyrido[1,2-a]pyrazin-6one $(24.7 \mathrm{mg}, 0.041 \mathrm{mmol})$ in 1,2-dichloroethane $(1.0 \mathrm{~mL})$ were added $N, N^{\prime}$ disuccinimidyl carbonate $(31.5 \mathrm{mg}, 0.123 \mathrm{mmol})$ and diisopropylethylamine $(0.07$ $\mathrm{mL}, 0.410 \mathrm{mmol})$. The reaction mixture was stirred at room temperature for $1 \mathrm{~h}$. 4-(2-Keto-1-benzimidazolinyl)piperidine $16(46.7 \mathrm{mg}, 0.215 \mathrm{mmol})$ was added and the solution was stirred at room temperature overnight. The solvent was evaporated in vacuum and the residue was purified by reverse phase preparative HPLC (column - XTERRA 30×150 mm S5; injection volume $-2000 \mu \mathrm{L}$, solvent A - methanol (10\%) - water (90\%) - TFA $(0.1 \%)$; solvent B - methanol $(90 \%)$ water (10\%) - TFA (0.1\%); flow rate $-25 \mathrm{~mL} / \mathrm{min}$; starting $\% \mathrm{~B}-30$, final $\% \mathrm{~B}-$ 100; gradient time $-20 \mathrm{~min}$, stop time $-25 \mathrm{~min})$ to give the title compound ( 21.3 mg, $59 \%$ yield) as colorless semisolid. ${ }^{1} \mathrm{H}$ NMR $(500 \mathrm{MHz}, \mathrm{MeOH}$ d4) $\delta 7.54(\mathrm{~s}$, 
2H), $7.33(\mathrm{~m}, 3 \mathrm{H}), 7.12-7.06(\mathrm{~m}, 5 \mathrm{H}), 7.00(\mathrm{t}, J=7.5 \mathrm{~Hz}, 1 \mathrm{H}), 4.65(\mathrm{~d}, J=13.5$ $\mathrm{Hz}, 1 \mathrm{H}), 4.50(\mathrm{~m}, 1 \mathrm{H}), 4.19(\mathrm{~m}, 2 \mathrm{H}), 3.78(\mathrm{~s}, 3 \mathrm{H}), 3.72(\mathrm{~m}, 1 \mathrm{H}), 3.62(\mathrm{~d}, J=11.5$ $\mathrm{Hz}, 1 \mathrm{H}), 3.30(\mathrm{~d}, J=13.5 \mathrm{~Hz}, 1 \mathrm{H}), 3.12-2.88(\mathrm{~m}, 4 \mathrm{H}), 2.53-2.30(\mathrm{~m}, 4 \mathrm{H}), 2.12(\mathrm{~d}$, $J=13.5 \mathrm{~Hz}, 1 \mathrm{H}), 1.90-1.77(\mathrm{~m}, 2 \mathrm{H}), 1.41-1.18(\mathrm{~m}, 4 \mathrm{H}) . \mathrm{MS}(\mathrm{ESI})$ calculated $\mathrm{m} / \mathrm{z}$ $765.14[\mathrm{M}+\mathrm{H}]^{+}$, found $\mathrm{m} / \mathrm{z} 764.93[\mathrm{M}+\mathrm{H}]^{+}$.

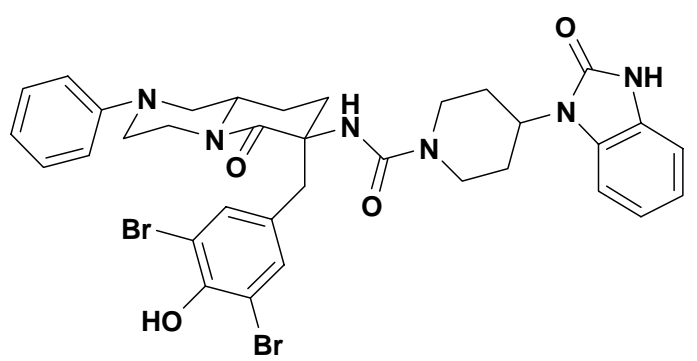

Trans-N-(7-(3,5-dibromo-4-hydroxybenzyl)-6-oxo-2-phenyl-octahydro-1Hpyrido[1,2-a]pyrazin-7-yl)-4-(2-oxo-2,3-dihydrobenzo[d]imidazol-1yl)piperidine-1-carboxamide (TFA salt) 2a: To a solution of trans- $N-(7-(3,5-$ dibromo-4-methoxybenzyl)-6-oxo-2-phenyl-octahydro-1H-pyrido[1,2-a]pyrazin-7yl)-4-(2-oxo-2,3-dihydrobenzo[d]imidazol-1-yl)piperidine-1-carboxamide 15a (8.0 $\mathrm{mg}, 0.010 \mathrm{mmol})$ in dichloromethane $(1.0 \mathrm{~mL})$ cooled to $-78^{\circ} \mathrm{C}$ was added $1.0 \mathrm{M}$ solution of boron tribromide in dichloromethane $(0.1 \mathrm{~mL}, 0.100 \mathrm{mmol})$. The reaction mixture was warmed to room temperature and stirred for $1.5 \mathrm{~h}$. Triethylamine $(0.5 \mathrm{~mL})$ was added at $-78^{\circ} \mathrm{C}$, followed by methanol $(3 \mathrm{~mL})$. The mixture was warmed to room temperature and stirred for $5 \mathrm{~min}$. The solvent was evaporated to dryness and the crude product was purified by reverse phase preparative HPLC (column - XTERRA 30×150 mm S5; injection volume - 2000 
$\mu \mathrm{L}$, solvent A - methanol (10\%) - water $(90 \%)$ - TFA $(0.1 \%)$; solvent B methanol $(90 \%)$ - water $(10 \%)$ - TFA $(0.1 \%)$; flow rate $-25 \mathrm{~mL} / \mathrm{min}$; starting \%B -20 , final $\% B-80$; gradient time $-20 \mathrm{~min}$, stop time $-25 \mathrm{~min}$ ) to give the title compound ( $6.5 \mathrm{mg}, 87 \%$ yield) as white semisolid. ${ }^{1} \mathrm{H} \mathrm{NMR}(500 \mathrm{MHz}, \mathrm{MeOH}$ d4) $\delta 7.43(\mathrm{~s}, 2 \mathrm{H}), 7.38-7.30(\mathrm{~m}, 3 \mathrm{H}), 7.15-7.06(\mathrm{~m}, 5 \mathrm{H}), 7.04(\mathrm{t}, J=7.0 \mathrm{~Hz}, 1 \mathrm{H}), 4.67$ $(\mathrm{d}, J=13.5 \mathrm{~Hz}, 1 \mathrm{H}), 4.48(\mathrm{~m}, 1 \mathrm{H}), 4.23-4.15(\mathrm{~m}, 2 \mathrm{H}), 3.79(\mathrm{~d}, J=11.0 \mathrm{~Hz}, 1 \mathrm{H})$, 3.78-3.69 $(\mathrm{m}, 1 \mathrm{H}), 3.61(\mathrm{~d}, J=11.5 \mathrm{~Hz}, 1 \mathrm{H}), 3.38-3.20(\mathrm{~m}, 2 \mathrm{H}), 3.10\left(\mathrm{td}, J_{1}=\right.$ 13.0 Hz, $\left.J_{2}=3.0 \mathrm{~Hz}, 1 \mathrm{H}\right), 3.03-2.90(\mathrm{~m}, 3 \mathrm{H}), 2.52-2.31(\mathrm{~m}, 2 \mathrm{H}), 2.10(\mathrm{~d}, J=13.5$ $\mathrm{Hz}, 1 \mathrm{H}), 1.85-1.75(\mathrm{~m}, 2 \mathrm{H}), 1.40-1.27(\mathrm{~m}, 3 \mathrm{H}), 1.22-1.10(\mathrm{~m}, 1 \mathrm{H}) . \mathrm{MS}(\mathrm{ESI})$ calculated $m / z 751.13[\mathrm{M}+\mathrm{H}]^{+}$, found $m / z 750.90[\mathrm{M}+\mathrm{H}]^{+}$.

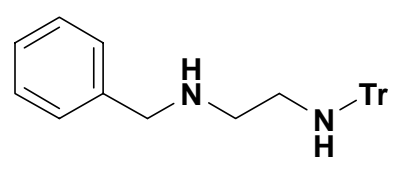

$\boldsymbol{N}$-benzyl- $\boldsymbol{N}$ '-tritylethane-1,2-diamine $\mathbf{6 b}$. To a solution of $\mathrm{N}-(2-$ aminoethyl)benzylamine $(2.00 \mathrm{~mL}, 0.013 \mathrm{~mol})$ in dichloromethane $(20 \mathrm{~mL})$ at $0^{\circ} \mathrm{C}$ was added triethylamine $(1.81 \mathrm{~mL}, 0.013 \mathrm{~mol})$ and trityl chloride $(3.624 \mathrm{~g}, 0.013$ mol). The reaction mixture was warmed to room temperature and stirred overnight. The solvent was evaporated and the residue was partitioned between ethylacetate and water. The organic layer was separated and the aqueous layer was extracted with ethylacetate. The combined organic layers were dried over anhydrous sodium sulfate, filtered and concentrated in vacuum. The crude product was purified by column chromatography on silica gel (hexanes - 
ethylacetate $-4: 1$ to $1: 1)$ to provide the title compound $(5.103 \mathrm{~g}, 100 \%$ yield) as colorless oil. ${ }^{1} \mathrm{H}$ NMR $\left(500 \mathrm{MHz}, \mathrm{CDCl}_{3}\right) \delta$ 7.70-7.00 (m, 20H), $3.70(\mathrm{~s}, 2 \mathrm{H}), 2.90$ (t, $J=5.0 \mathrm{~Hz}, 2 \mathrm{H}$ ), 2.40 (t, $J=5.0 \mathrm{~Hz}, 2 \mathrm{H}$ ), 1.70 (br s, 2H). MS (ESI) calculated $m / z 393.24[\mathrm{M}+\mathrm{H}]^{+}$, found $m / z 393.14[\mathrm{M}+\mathrm{H}]^{+}$.

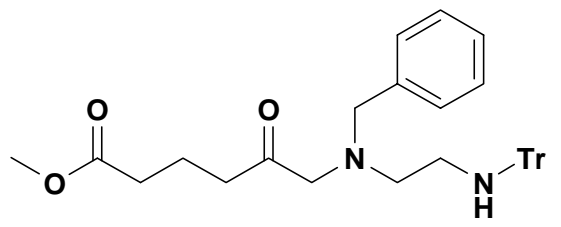

\section{Methyl 6-(benzyl(2-(tritylamino)ethyl)amino)-5-oxohexanoate $7 \mathrm{~b}$. To a} solution of benzyl $N$-benzyl- $N$ '-tritylethane-1,2-diamine $6 \mathrm{~b}(65.16 \mathrm{~g}, 0.166 \mathrm{~mol})$ and methyl 6-bromo-5-oxohexanoate $(65.00 \mathrm{~g}, 0.275 \mathrm{~mol})$ in acetone $(1300 \mathrm{~mL})$ were added potassium carbonate $(52.80 \mathrm{~g}, 0.382 \mathrm{~mol})$ and potassium iodide $(13.78 \mathrm{~g}, 0.083 \mathrm{~mol})$. The reaction mixture was stirred at room temperature overnight. Acetone was removed under reduced pressure and the residue was partitioned between water and ethylacetate. The organic layer was separated and the aqueous layer was extracted with ethylacetate. The combined organic extracts were dried over anhydrous sodium sulfate, filtered and concentrated in vacuum. The crude product was purified by column chromatography on silica gel (hexanes - ethylacetate $-4: 1$ to $1: 4)$ to provide the title compound $(79.92 \mathrm{~g}, 90 \%$ yield) as light brown oil. ${ }^{1} \mathrm{H} \mathrm{NMR}\left(500 \mathrm{MHz}, \mathrm{CDCl}_{3}\right) \delta$ 7.50-7.10 (m, 20H), $3.62(\mathrm{~s}$, 3H), 3.47 (s, 2H), $3.02(\mathrm{~s}, 2 \mathrm{H}), 2.68(\mathrm{t}, J=7.0 \mathrm{~Hz}, 2 \mathrm{H}), 2.38(\mathrm{t}, J=7.0 \mathrm{~Hz}, 2 \mathrm{H})$, 2.28 (br s, 1H), 2.28 (t, $J=7.0 \mathrm{~Hz}, 2 \mathrm{H}$ ), 2.28 (t, $J=7.0 \mathrm{~Hz}, 2 \mathrm{H}$ ), 1.82 (q, $J=7.0$ $\mathrm{Hz}, 2 \mathrm{H}) . \mathrm{MS}(\mathrm{ESI})$ calculated $m / z 535.30[\mathrm{M}+\mathrm{H}]^{+}$, found $m / z 535.21[\mathrm{M}+\mathrm{H}]^{+}$. 


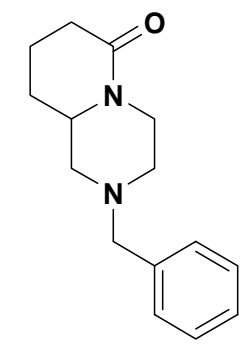

2-Benzyl-octahydropyrido[1,2-a]pyrazin-6-one (TFA salt) 3b. To a solution of methyl 6-(benzyl(2-(tritylamino)ethyl)amino)-5-oxohexanoate 7b (88.80 g, 0.116 mol) in methanol $(65 \mathrm{~mL})$ was added a $2.0 \mathrm{M}$ solution of hydrogen chloride in 1.4dioxane $(65 \mathrm{~mL})$. The reaction mixture was stirred at reflux for $1 \mathrm{~h}$. The solvent was evaporated in vacuum. Methanol $(650 \mathrm{~mL})$ was added, followed by sodium cyanoborohydride $(22.25 \mathrm{~g}, 0.354 \mathrm{~mol})$, and the resulting solution was adjusted to $\mathrm{pH} 5$ by dropwise addition of $4 \mathrm{~N}$ hydrogen chloride in 1,4-dioxane. The reaction mixture was refluxed for $3.5 \mathrm{~h}$. The excess of sodium cyanoborohydride was destroyed by addition of $4 \mathrm{~N}$ hydrogen chloride in 1,4-dioxane at $0^{\circ} \mathrm{C}$ until bubbling stopped. The reaction mixture was carefully poured into an aqueous potassium carbonate solution and extracted with dichloromethane. The combined organic layers were dried over anhydrous sodium sulfate. Ensuing purification by reverse phase preparative HPLC (column - XTERRA 30×150 mm S5; injection volume - $2000 \mu \mathrm{L}$, solvent $\mathrm{A}$ - methanol $(10 \%)$ - water $(90 \%)-\operatorname{TFA}(0.1 \%)$; solvent B - methanol (90\%) - water (10\%) - TFA (0.1\%); flow rate $-25 \mathrm{~mL} / \mathrm{min}$; starting $\% B-20$, final $\% B-80$; gradient time -20 min, stop time -25 min) provided the desired product as colorless oil (35.33 g, 85\%). ${ }^{1} \mathrm{H}$ NMR $(500 \mathrm{MHz}$, $\left.\mathrm{CDCl}_{3}\right) \delta 7.30(\mathrm{~s}, 5 \mathrm{H}), 4.60\left(\mathrm{ddd}, J_{1}=13.0 \mathrm{~Hz}, J_{2}=3.0 \mathrm{~Hz}, J_{3}=2.0 \mathrm{~Hz}, 1 \mathrm{H}\right), 3.53$ 
(d, $J=13.0 \mathrm{~Hz}, 1 \mathrm{H}), 3.47(\mathrm{~d}, J=13.0 \mathrm{~Hz}, 1 \mathrm{H}), 3.43(\mathrm{~m}, 1 \mathrm{H}), 2.89-2.78(\mathrm{~m}, 2 \mathrm{H})$,

$2.72\left(\mathrm{ddd}, J_{1}=13.0 \mathrm{~Hz}, J_{2}=12.0 \mathrm{~Hz}, J_{3}=3.0 \mathrm{~Hz}, 1 \mathrm{H}\right), 2.50-2.20(\mathrm{~m}, 2 \mathrm{H}), 2.02$

(td, $\left.J_{1}=12.0 \mathrm{~Hz}, J_{2}=3 \mathrm{~Hz}, 1 \mathrm{H}\right), 1.95-1.55(\mathrm{~m}, 3 \mathrm{H}), 1.80(\mathrm{t}, J=11.0 \mathrm{~Hz}, 1 \mathrm{H})$, $1.40(\mathrm{~m}, 1 \mathrm{H}) . \mathrm{MS}(\mathrm{ESI})$ calculated $\mathrm{m} / \mathrm{z} 245.17[\mathrm{M}+\mathrm{H}]^{+}$, found $\mathrm{m} / \mathrm{z} 245.47[\mathrm{M}+\mathrm{H}]^{+}$

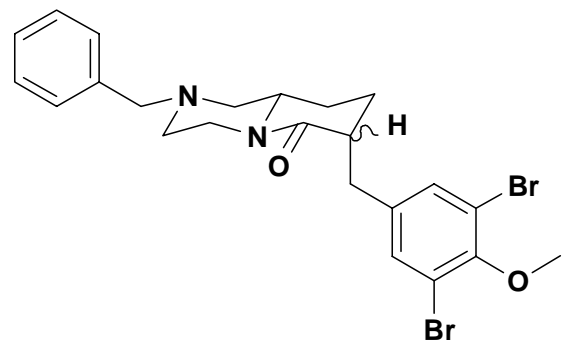

\section{7-(3,5-dibromo-4-methoxybenzyl)-2-benzyl-octahydropyrido[1,2-a]pyrazin-6-}

one 11b: To a $2.0 \mathrm{M}$ solution of lithium diisopropylamide in heptane-THFethylbenzene $(2.25 \mathrm{~mL})$ cooled to $-78^{\circ} \mathrm{C}$ was added THF $(3 \mathrm{~mL})$ and 2benzyloctahydropyrido[1,2-a]pyrazin-6-one $3 \mathbf{b}(1.000 \mathrm{~g}, 4.093 \mathrm{mmol})$ in THF (10 $\mathrm{mL}$ ) via cannula. The resulting solution was stirred at $-78^{\circ} \mathrm{C}$ for $2 \mathrm{~h} 15 \mathrm{~min}$. A solution of 1,3-dibromo-5-(iodomethyl)-2-methoxybenzene 10 (1.827 g, 4.502 $\mathrm{mmol})$ in THF $(10 \mathrm{~mL})$ was cannulated, the reaction mixture was warmed to $20^{\circ} \mathrm{C}$ and stirred overnight, while allowing to warm to $+10^{\circ} \mathrm{C}$. Aqueous ammonium chloride and dichloromethane were added at $0^{\circ} \mathrm{C}$. The organic phase was separated and the aqueous phase was extracted with dichloromethane. The combined organic extracts were dried over anhydrous sodium sulfate, filtered and concentrated in vacuum. The crude product was purified by column chromatography on silica gel (hexanes - ethylacetate - $6: 1$ to $3: 1$ ) to provide the 
title product as an 1.4:1 mixture of diastereomers. Diastereomer A (0.898 g, 42\%, colorless oil): ${ }^{1} \mathrm{H}$ NMR $\left(500 \mathrm{MHz}, \mathrm{C}_{6} \mathrm{D}_{6}\right) \delta 7.27-7.12(\mathrm{~m}, 5 \mathrm{H}), 7.22(\mathrm{~s}, 2 \mathrm{H})$, $4.77(\mathrm{~d}, J=13.5 \mathrm{~Hz}, 1 \mathrm{H}), 3.59(\mathrm{~s}, 3 \mathrm{H}), 3.28\left(\mathrm{dd}, J_{1}=14.0 \mathrm{~Hz}, J_{2}=4.5 \mathrm{~Hz}, 1 \mathrm{H}\right)$, $3.24(\mathrm{~d}, J=13.0 \mathrm{~Hz}, 1 \mathrm{H}), 3.12(\mathrm{~d}, J=13.5 \mathrm{~Hz}, 1 \mathrm{H}), 3.93-3.86(\mathrm{~m}, 1 \mathrm{H}), 2.57(\mathrm{~m}$, $1 \mathrm{H}), 2.50-2.45(\mathrm{~m}, 1 \mathrm{H}), 2.42(\mathrm{~d}, J=11.0 \mathrm{~Hz}, 1 \mathrm{H}), 2.34\left(\mathrm{dd}, J_{1}=14.0 \mathrm{~Hz}, J_{2}=9.0\right.$ $\mathrm{Hz}, 1 \mathrm{H}), 1.98-1.90(\mathrm{~m}, 1 \mathrm{H}), 1.73(\mathrm{~m}, 1 \mathrm{H}), 1.34(\mathrm{t}, J=11.0 \mathrm{~Hz}, 1 \mathrm{H}), 1.15-1.07(\mathrm{~m}$, $1 \mathrm{H}), \quad 1.05-1.00(\mathrm{~m}, 1 \mathrm{H}), 0.81-0.65(\mathrm{~m}, 2 \mathrm{H}) . \mathrm{MS}(\mathrm{ESI})$ calculated $\mathrm{m} / \mathrm{z} 521.05$ $[\mathrm{M}+\mathrm{H}]^{+}$, found $\mathrm{m} / \mathrm{z} 521.11[\mathrm{M}+\mathrm{H}]^{+}$. Diastereomer B $(0.620 \mathrm{~g}, 29 \%$, colorless oil): ${ }^{1} \mathrm{H}$ NMR $\left(500 \mathrm{MHz}, \mathrm{C}_{6} \mathrm{D}_{6}\right) \delta 7.27(\mathrm{~d}, J=7.5 \mathrm{~Hz}, 2 \mathrm{H}), 7.21(\mathrm{t}, J=8.0 \mathrm{~Hz}, 2 \mathrm{H}), 7.21$ (s, 2H), 7.12 (t, $J=7.0 \mathrm{~Hz}, 1 \mathrm{H}), 4.80-4.65(\mathrm{~m}, 1 \mathrm{H}), 3.60$ (s, 3H), 3.27 (d, $J=13.0$ $\mathrm{Hz}, 1 \mathrm{H}), 3.14(\mathrm{~d}, J=13.0 \mathrm{~Hz}, 1 \mathrm{H}), 3.02\left(\mathrm{dd}, J_{1}=14.0 \mathrm{~Hz}, J_{2}=4.5 \mathrm{~Hz}, 1 \mathrm{H}\right), 2.97-$ $2.91(\mathrm{~m}, 1 \mathrm{H}), 2.56-2.45(\mathrm{~m}, 3 \mathrm{H}), 2.28(\mathrm{~d}, J=10.5 \mathrm{~Hz}, 1 \mathrm{H}), 2.20-2.12(\mathrm{~m}, 1 \mathrm{H})$, 1.82-1.74 $(\mathrm{m}, 1 \mathrm{H}), 1.41(\mathrm{t}, J=11.0 \mathrm{~Hz}, 1 \mathrm{H}), 1.02-0.88(\mathrm{~m}, 4 \mathrm{H}) . \mathrm{MS}(\mathrm{ESI})$ calculated $m / z 521.05[\mathrm{M}+\mathrm{H}]^{+}$, found $m / z 521.12[\mathrm{M}+\mathrm{H}]^{+}$.

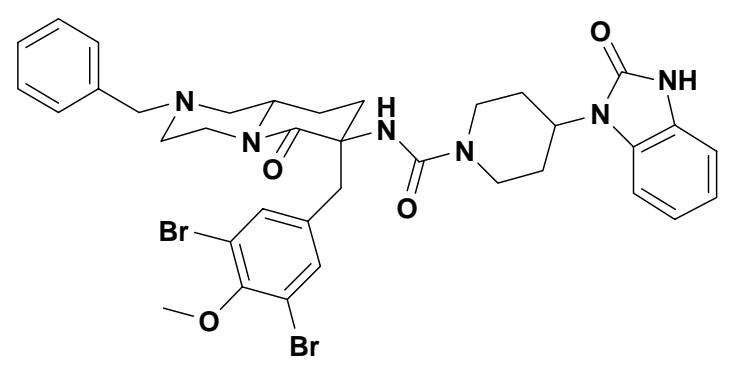

Trans-N-(7-(3,5-dibromo-4-methoxybenzyl)-2-benzyl-6-oxo-octahydro-1Hpyrido[1,2-a]pyrazin-7-yl)-4-(2-oxo-2,3-dihydrobenzo[d]imidazol-1yl)piperidine-1-carboxamide (TFA salt) 15 b. To a $2.0 \mathrm{M}$ solution of lithium 
diisopropylamide in heptane - THF - ethylbenzene $(1.64 \mathrm{~mL}, 3.284 \mathrm{mmol})$ cooled to $-78^{\circ} \mathrm{C}$ was added $\mathrm{THF}(2.0 \mathrm{~mL})$ and 7-(3,5-dibromo-4-methoxybenzyl)-2benzyl-octahydropyrido[1,2-a]pyrazin-6-one 11b (1.429 g, $2.737 \mathrm{mmol})$ in THF $(18 \mathrm{~mL})$ via cannula. The resulting solution was stirred at $-78^{\circ} \mathrm{C}$ for $2 \mathrm{~h} 10 \mathrm{~min}$, then - warmed to $-20^{\circ} \mathrm{C}$. Propyl nitrate $(0.34 \mathrm{~mL}, 3.284 \mathrm{mmol})$ was added and the reaction mixture was allowed to warm to $+5^{\circ} \mathrm{C}$ over $3 \mathrm{~h}$. Aqueous ammonium chloride and dichloromethane were added at $0^{\circ} \mathrm{C}$. The organic phase was separated and the aqueous phase was extracted with dichloromethane. The combined organic extracts were dried over sodium sulfate and concentrated in vacuum to provide the crude product as an $8: 1$ mixture of diastereomers (37\% combined yield, as determined by LCMS). Concentrated aqueous solution of hydrogen chloride $(10 \mathrm{~mL})$ and 1,4-dioxane $(10 \mathrm{~mL})$ were added to dissolve the crude product. Zinc was added by small portions to the resulting solution until the conversion to the product was complete (control by LCMS). The solvent was concentrated in vacuum and the residue was purified by a reverse phase preparative HPLC (column - XTERRA $30 \times 150$ mm S5; injection volume - 2000 $\mu \mathrm{L}$, solvent A - methanol (10\%) - water $(90 \%)$ - TFA $(0.1 \%)$; solvent B methanol $(90 \%)$ - water $(10 \%)$ - TFA (0.1\%); flow rate $-25 \mathrm{~mL} / \mathrm{min}$; starting \%B -20 , final $\% B-80$; gradient time -20 min, stop time $-25 \mathrm{~min}$ ) to provide transdiastereomer (double TFA salt) 13b (565.8 mg, 73\%) as white solid and cisdiastereomer (double TFA salt) 14b $(69.8 \mathrm{mg}, 9.1 \%)$ as white solid. To a suspension of trans- 7-(3,5-dibromo-4-methoxybenzyl)-7-amino-2-benzyloctahydropyrido[1,2-a]pyrazin-6-one $\quad 13 b \quad(5.5 \quad \mathrm{mg}, \quad 0.009 \mathrm{mmol})$ in $1,2-$ 
dichloroethane $(0.3 \mathrm{~mL})$ were added $N_{,} N^{\prime}$-disuccinimidyl carbonate $(6.9 \mathrm{mg}$, $0.027 \mathrm{mmol})$ and diisopropylethylamine $(0.02 \mathrm{~mL}, 0.089 \mathrm{mmol})$. The reaction mixture was stirred at room temperature for 1 h. 4-(2-Keto-1benzimidazolinyl)piperidine $16(10.2 \mathrm{mg}, 0.047 \mathrm{mmol})$ was added and the solution was stirred at room temperature overnight. The solvent was evaporated in vacuum and the residue was purified by reverse phase preparative HPLC (column - XTERRA 30×150 mm S5; injection volume - $2000 \mu \mathrm{L}$, solvent A methanol $(10 \%)$ - water $(90 \%)$ - TFA $(0.1 \%)$; solvent B - methanol $(90 \%)$ water (10\%) - TFA (0.1\%); flow rate $-25 \mathrm{~mL} / \mathrm{min}$; starting $\% \mathrm{~B}-30$, final $\% \mathrm{~B}-$ 100; gradient time $-20 \mathrm{~min}$, stop time $-25 \mathrm{~min}$ ) to give the title compound (4.9 mg, 70\% yield) as colorless semisolid. ${ }^{1} \mathrm{H}$ NMR $(500 \mathrm{MHz}, \mathrm{MeOH}$ d4) $\delta 7.55$ (s, $5 \mathrm{H}), 7.53(\mathrm{~s}, 2 \mathrm{H})$, 7.33-7.28 (m, 1H), 7.10-7.02 (m, 3H), 4.27-4.20 (m, 1H), 4.48 (m, 1H), $4.42(\mathrm{~m}, 1 \mathrm{H}), 4.21-4.05(\mathrm{~m}, 2 \mathrm{H}), 3.78(\mathrm{~s}, 3 \mathrm{H}), 3.69(\mathrm{~m}, 1 \mathrm{H}), 3.50(\mathrm{~d}, J=$ $12.0 \mathrm{~Hz}, 1 \mathrm{H}), 3.20(\mathrm{~d}, J=14.0 \mathrm{~Hz}, 1 \mathrm{H}), 3.11-2.92(\mathrm{~m}, 4 \mathrm{H}), 2.69(\mathrm{~m}, 1 \mathrm{H}), 2.54-$ $2.28(\mathrm{~m}, 3 \mathrm{H}), 2.08-1.98(\mathrm{~m}, 1 \mathrm{H}), 1.91-1.73(\mathrm{~m}, 3 \mathrm{H}), 1.42-1.25(\mathrm{~m}, 4 \mathrm{H}) . \mathrm{MS}(\mathrm{ESI})$ calculated $m / z 779.16[\mathrm{M}+\mathrm{H}]^{+}$, found $m / z 779.02[\mathrm{M}+\mathrm{H}]^{+}$.

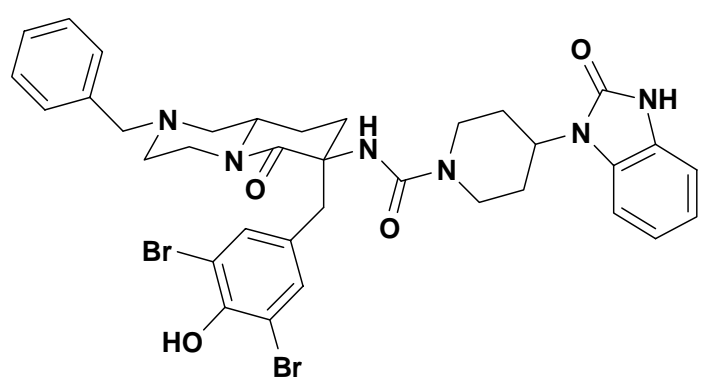

Trans-N-(7-(3,5-dibromo-4-hydroxybenzyl)-6-oxo-2-benzyl-octahydro-1H- 


\section{pyrido[1,2-a]pyrazin-7-yl)-4-(2-oxo-2,3-dihydrobenzo[d]imidazol-1-}

yl)piperidine-1-carboxamide (TFA salt) 2b: To a solution of trans- $N-(7-(3,5-$ dibromo-4-methoxybenzyl)-6-oxo-2-benzyl-octahydro-1 $H$-pyrido[1,2-a]pyrazin-7yl)-4-(2-oxo-2,3-dihydrobenzo[d]imidazol-1-yl)piperidine-1-carboxamide $\mathbf{1 5 b}$ in dichloromethane $(1.0 \mathrm{~mL})$ cooled to $-78^{\circ} \mathrm{C}$ was added $1.0 \mathrm{M}$ solution of boron tribromide in dichloromethane $(0.1 \mathrm{~mL}, 0.100 \mathrm{mmol})$. The reaction mixture was warmed to room temperature and stirred for $1.5 \mathrm{~h}$. Triethylamine $(0.5 \mathrm{~mL})$ was added at $-78^{\circ} \mathrm{C}$, followed by methanol $(3 \mathrm{~mL})$. The mixture was warmed to room temperature and stirred for $5 \mathrm{~min}$. The solvent was evaporated to dryness and the crude product was purified by reverse phase preparative HPLC (column XTERRA $30 \times 150 \mathrm{~mm} \mathrm{S5}$; injection volume $-2000 \mu \mathrm{L}$, solvent $\mathrm{A}$ - methanol $(10 \%)$ - water $(90 \%)$ - TFA $(0.1 \%)$; solvent B - methanol $(90 \%)$ - water $(10 \%)$ TFA (0.1\%); flow rate $-25 \mathrm{~mL} / \mathrm{min}$; starting $\% \mathrm{~B}-30$, final \%B - 100; gradient time $-20 \mathrm{~min}$, stop time $-25 \mathrm{~min}$ ) to give the title compound (TFA salt) (6.5 mg, $87 \%$ yield) as white semisolid. ${ }^{1} \mathrm{H}$ NMR $(500 \mathrm{MHz}, \mathrm{MeOH}$ d4) $\delta 7.55(\mathrm{~s}, 5 \mathrm{H}), 7.45$ (s, 2H), 7.32-7.27 (m, 1H), 7.10-7.02 (m, 3H), 4.82-4.73 (m, 1H), $4.48(\mathrm{~m}, 1 \mathrm{H})$, $4.41(\mathrm{~m}, 1 \mathrm{H}), 4.17(\mathrm{~m}, 2 \mathrm{H}), 3.83-3.73(\mathrm{~m}, 1 \mathrm{H}), 3.71-3.64(\mathrm{~m}, 1 \mathrm{H}), 3.52-3.45(\mathrm{~m}$, $1 \mathrm{H}), 3.23(\mathrm{~d}, J=14.5 \mathrm{~Hz}, 1 \mathrm{H}), 3.15-2.92(\mathrm{~m}, 4 \mathrm{H}), 2.62(\mathrm{~m}, 1 \mathrm{H}), 2.52-2.40(\mathrm{~m}$, 2H), 2.40-2.29 (m, 1H), $2.03(\mathrm{~d}, J=14.0 \mathrm{~Hz}, 1 \mathrm{H}), 1.89-1.75(\mathrm{~m}, 2 \mathrm{H}), 1.42-1.20$ (m, 4H). MS (ESI) calculated $m / z 765.14[\mathrm{M}+\mathrm{H}]^{+}$, found $m / z 765.08[\mathrm{M}+\mathrm{H}]^{+}$.

Computational Details. To assess the ability of compound $2 \mathbf{a}$ to adopt conformations similar to potent CGRP antagonist compound 1, conformational 
searches for compounds $\mathbf{1}$ and $\mathbf{2 a}$ were performed with MacroModel version 8.6 (Schrödinger, L.L.C., Portland, OR). These studies used the MCMM algorithm, the MMFFs force-field, and the GB/SA implicit water solvation model. ${ }^{1}$ Each search was run for 5000 steps, with a maximum of 5000 steps of PRCG minimization for each structure generated. During each search, structures within $100 \mathrm{~kJ} / \mathrm{mol}$ of the current global minimum were retained. The resultant conformations of compounds $\mathbf{1}$ and $\mathbf{2 a}$ were then subjected to energy minimization using the SAM1 semiempirical method ${ }^{2}$ and the $\mathrm{COSMO}^{3}$ implicit solvation model in Ampac version 6.7 (keywords: SAM1 GRAD PRECISE SCFCRT $=0$ BONDS T=4H CHARGE=0 COSMO) (Semichem, Inc., Shawnee, KS). The SAM1/COSMO minimized conformers of compound 1 were then clustered using an in-house SPL (SYBYL ${ }^{\circledR}$ Programming Language) script in SYBYL ${ }^{\circledR}$ version 6.9 (Tripos, Inc., St. Louis, MO). Briefly, conformers were ranked in ascending order based on predicted energies. The lowest energy conformer was then selected as the first reference conformer, and all other conformers were fit to it based on RMS for a selected set of atoms. Each conformer within an RMS of $0.5 \AA$ of the reference conformer was assigned to the cluster. The next lowest energy conformer that was not assigned to the first cluster was then selected as the reference structure for the second cluster, and the fitting and cluster assignment process was repeated. This procedure was

(1) For descriptions of the force-field and computational algorithms used, see MacroModel 8.5 User Manual, 2003, Schrödinger, L.L.C., Portland, OR, and references therein.

(2) Dewar, M.J.S.; Jie, C.; Yu, J. Tetrahedron 1993, 49, 5003.

(3) Klamt, A. J. Chem. Soc. Perkin 2 1993, 799; Klamt, A. J. Chem. Phys. 1995, 99, 2224; Klamt, A. J. Chem. Phys. 1996, 100, 3349. 
repeated until all conformers were assigned to clusters (many clusters contained only a single member).

The ability of compound $2 \mathrm{a}$ to mimic the shape and electrostatic properties of compound $\mathbf{1}$ was evaluated by comparing the reference conformers from the ten lowest energy clusters from compound $\mathbf{1}$ to all conformers of compound $\mathbf{2 a}$ with energies within $5.0 \mathrm{kcal} / \mathrm{mol}$ of the lowest energy structure identified. This was done using the molecular superposition program phase, ${ }^{4}$ which is an in-house program that superimposes compounds by matching classes of atoms (e.g. aromatic, hydrogen-bond donor, acid, etc.) in a reference structure to similar classes in a query structure. Overlays are scored based on the number of atoms in the reference structure that can be fit within a certain distance to atoms of the same class in the query structure. This is very similar to the program SQ. ${ }^{5}$ Highscoring phase overlays were further evaluated visually.

For representative conformers from the ten lowest energy clusters for compound $\mathbf{1}$, reasonable overlays with conformers of compound $\mathbf{2 a}$ were identified. In each case, the energy of the compound $\mathbf{2 a}$ conformer was within 5.0 $\mathrm{kcal} / \mathrm{mol}$ of the energy of the most stable conformer found. The overlay of the best-fitting conformer of compound $\mathbf{2 a}$ with a low energy conformer of compound $\mathbf{1}$ is shown in Figure 2. The energies of the conformers of compounds 1 and $\mathbf{2 a}$ shown in Figure 2 are 0.5 and $1.3 \mathrm{kcal} / \mathrm{mol}$ above those of the lowest energy conformers identified for $\mathbf{1}$ and $\mathbf{2 a}$, respectively. Although none of the ten conformers of compound 1 used as references necessarily represent the

(4) Phase, Bristol-Myers Squibb in-house program developed by Y. Sun.

(5) Miller, Michael D.; Sheridan, Robert P.; Kearsley, Simon K. J. Med. Chem. 1999, 42, 1505. 
bioactive conformation of compound $\mathbf{1}$, the ability of compound $\mathbf{2 a}$ to adopt conformations similar to several different low energy conformations of compound 1 suggests that compound $\mathbf{2 a}$ should be a reasonable mimic of compound $\mathbf{1}$.

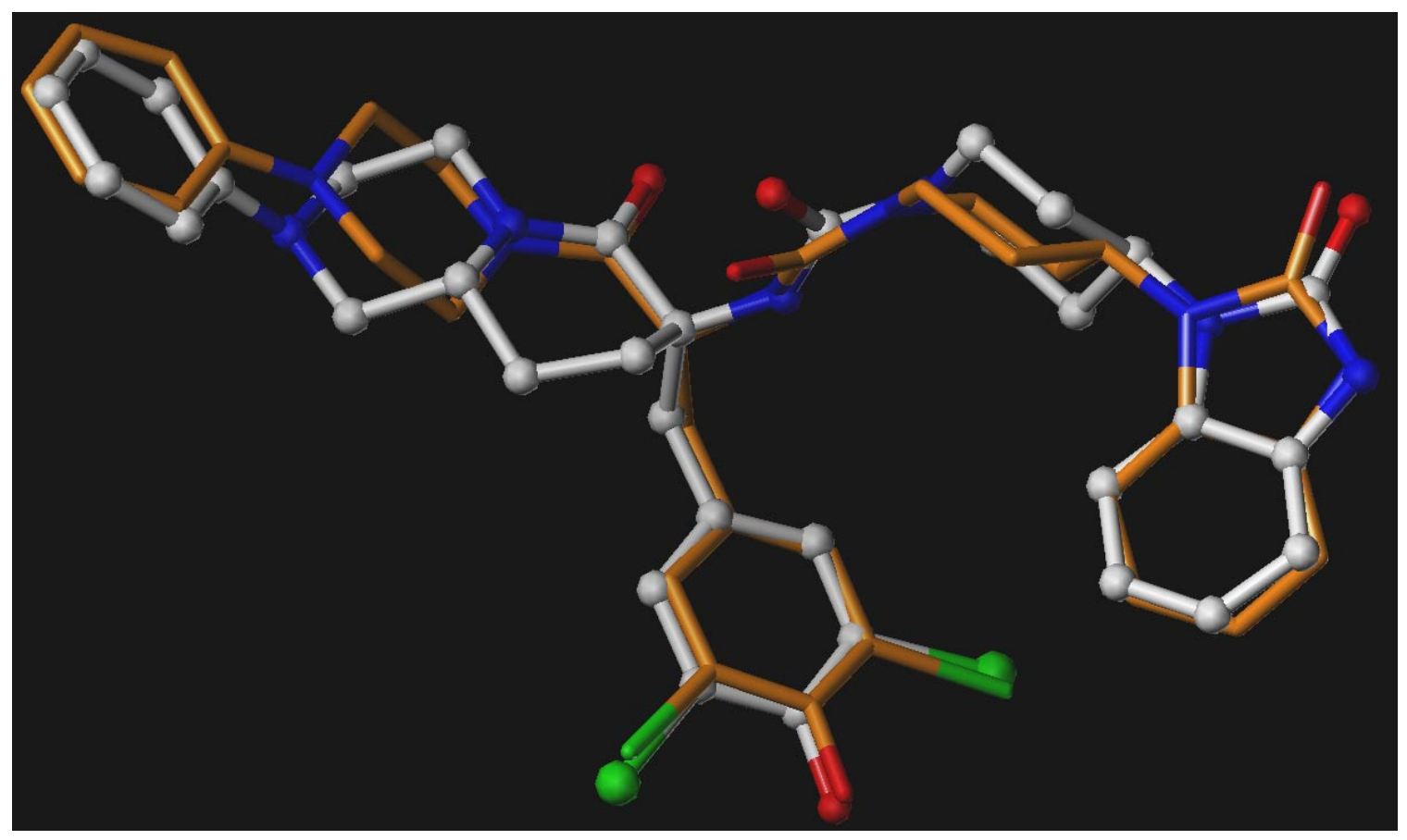

Figure 2. Overlay of predicted low energy conformations of potent CGRP antagonist $\mathbf{1}$ (stick rendering) and compound $\mathbf{2 a}$ (ball and stick rendering). 


\section{Cartesian Coordinates for the Conformers of Compounds 1 and 2a Shown in}

\section{Figure 2.}

\section{Compound 1.}

\begin{tabular}{|c|c|c|c|}
\hline $\mathrm{N}$ & 0.0000 & 0.0000 & 0.0000 \\
\hline $\mathrm{C}$ & 1.4609 & 0.0000 & 0.0000 \\
\hline $\mathrm{C}$ & 2.0334 & 1.4476 & 0.0000 \\
\hline $\mathrm{N}$ & 1.4145 & 2.2793 & -1.0257 \\
\hline $\mathrm{C}$ & -0.0394 & 2.2694 & -1.0469 \\
\hline $\mathrm{C}$ & -0.6123 & 0.8214 & -1.0416 \\
\hline $\mathrm{C}$ & 2.1894 & 3.1344 & -1.7900 \\
\hline $\mathrm{C}$ & 1.5175 & 4.0799 & -2.8716 \\
\hline $\mathrm{H}$ & 0.5001 & 3.6925 & -3.1447 \\
\hline $\mathrm{H}$ & -0.4289 & 2.8359 & -0.1649 \\
\hline $\mathrm{C}$ & -0.6777 & -1.1491 & 0.4412 \\
\hline C & -0.0040 & -2.1430 & 1.2380 \\
\hline $\mathrm{C}$ & -0.7225 & -3.2392 & 1.7584 \\
\hline C & -2.1089 & -3.3940 & 1.5138 \\
\hline C & -2.7758 & -2.4213 & 0.7290 \\
\hline C & -2.0881 & -1.3134 & 0.1934 \\
\hline 0 & 3.4593 & 3.1515 & -1.6348 \\
\hline $\mathrm{N}$ & 2.3398 & 4.0936 & -4.0514 \\
\hline C & 1.4420 & 5.4884 & -2.1938 \\
\hline
\end{tabular}



$\begin{array}{llll}\text { C } & 0.5657 & 6.4347 & -2.9934\end{array}$
$\begin{array}{llll}\text { C } & 1.1645 \quad 7.5202 & -3.6903\end{array}$
$\begin{array}{llll}\text { C } & 0.3432 & 8.4329 & -4.3829\end{array}$
$\begin{array}{lrrr}\text { C } & -1.0738 & 8.2836 & -4.4235\end{array}$
$\begin{array}{llll}\text { C } & -1.6472 & 7.1874 & -3.7147\end{array}$
C $\quad-0.8479 \quad 6.2711 \quad-3.0020$
Br $\quad 1.1641 \quad 9.9418 \quad-5.3117$
Br $-3.5812 \quad 6.9644 \quad-3.7325$
$\begin{array}{llll}0 & -1.9419 & 9.1377 & -5.0821\end{array}$
$\begin{array}{llll}\text { C } & 2.0439 & 3.3279 & -5.1770\end{array}$
$\begin{array}{llll}\mathrm{N} & 2.9727 & 3.2584 & -6.2280\end{array}$
$\begin{array}{llll}0 & 0.9516 & 2.6357 & -5.2251\end{array}$

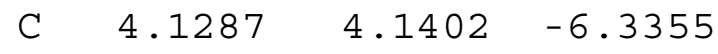
$\begin{array}{llll}\text { C } & 3.9435 & 5.2491 & -7.4040\end{array}$
$\begin{array}{llll}\text { C } & 3.5533 \quad 4.6003 & -8.7688\end{array}$
$\begin{array}{llll}\text { C } & 2.2898 \quad 3.7025 & -8.6017\end{array}$
$\begin{array}{llll}\text { C } & 2.5312 & 2.6548 & -7.4846\end{array}$
$\mathrm{N} \quad 3.3469 \quad 5.6090 \quad-9.8062$
C $\quad 4.3202 \quad 5.9124-10.8000$
$\mathrm{N} \quad 3.8631 \quad 7.0157-11.5652$
C $\quad 2.6561 \quad 7.4931-10.9979$
$\begin{array}{llll}\text { C } & 2.3172 & 6.5915 & -9.8844\end{array}$
$\begin{array}{llll}\text { C } & 1.8272 & 8.5770 & -11.3547\end{array}$
C $\quad 0.6463 \quad 8.7536-10.5851$ 


\begin{tabular}{|c|c|c|c|}
\hline C & 0.3108 & 7.8850 & -9.5190 \\
\hline C & 1.1299 & 6.7874 & -9.14 \\
\hline D & 5.3930 & 5.2551 & -11.041 \\
\hline 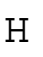 & 1.8348 & -0.5043 & 0.922 \\
\hline & 1.8628 & -0.5706 & -0.87 \\
\hline 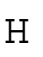 & 3.1299 & 1.3844 & -0.18 \\
\hline 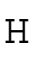 & 1.8840 & 1.9199 & 1.003 \\
\hline I & -1.7090 & 0.9030 & -0.856 \\
\hline I & -0.4789 & 0.3536 & -2.050 \\
\hline $\mathrm{H}$ & -0.4254 & 2.7692 & -1.963 \\
\hline I & -2.6523 & -4.2481 & 1.919 \\
\hline $\mathrm{H}$ & -3.8463 & -2.5249 & 0.526 \\
\hline 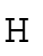 & -2.6396 & -0.5873 & -0.407 \\
\hline I & 1.0643 & -2.0621 & 1.44 \\
\hline I & -0.1885 & -3.9817 & 2.359 \\
\hline$T$ & 1.0063 & 5.3754 & -1.179 \\
\hline H & 2.4498 & 5.9341 & -2.068 \\
\hline $\mathrm{H}$ & 3.2225 & 4.5642 & -3.999 \\
\hline I & 2.2461 & 7.6573 & -3.693 \\
\hline $\mathrm{H}$ & -1.3290 & 5.4516 & $-2.46^{7}$ \\
\hline $\mathrm{H}$ & 3.1854 & 5.9885 & -7.07 \\
\hline $\mathrm{H}$ & 4.9054 & 5.7989 & -7.49 \\
\hline I & 5.0060 & 3.4983 & -6.59 \\
\hline & 48 & 6146 & $-5 \cdot 3$ \\
\hline
\end{tabular}




$\begin{array}{llll}\mathrm{H} & 3.3165 & 1.9241 & -7.7965 \\ \mathrm{H} & 1.5932 & 2.0811 & -7.3111 \\ \mathrm{H} & 1.3878 & 4.3133 & -8.3678 \\ \mathrm{H} & 2.0749 & 3.1572 & -9.5468 \\ \mathrm{H} & 4.4077 & 3.9617 & -9.1305 \\ \mathrm{H} & -1.3726 & 9.7651 & -5.5665 \\ \mathrm{H} & 4.4413 & 7.5265 & -12.1915 \\ \mathrm{H} & -0.0147 & 9.5870 & -10.8308 \\ \mathrm{H} & -0.6059 & 8.0593 & -8.9525 \\ \mathrm{H} & 0.8526 & 6.1218 & -8.3273 \\ \mathrm{H} & 2.0820 & 9.2438 & -12.1760\end{array}$

Compound 2a.

$\begin{array}{lrrr}\mathrm{N} & -0.3221 & 0.5805 & 0.5846 \\ \mathrm{C} & 1.1013 & 0.8246 & 0.8070 \\ \mathrm{C} & 1.9044 & 0.9527 & -0.5234 \\ \mathrm{~N} & 1.2713 & 1.8829 & -1.4551 \\ \mathrm{C} & -0.1548 & 1.6615 & -1.6952 \\ \mathrm{C} & -0.9275 & 1.5481 & -0.3259 \\ \mathrm{C} & 2.0518 & 2.8015 & -2.1321 \\ \mathrm{C} & 1.3936 & 3.8435 & -3.1445 \\ \mathrm{C} & 0.0640 & 3.2410 & -3.6925 \\ \mathrm{C} & -0.8281 & 2.7795 & -2.5346\end{array}$




$$
\begin{aligned}
& \begin{array}{llll}
\text { C } & -0.8591 & -0.7050 & 0.7367
\end{array} \\
& \begin{array}{llll}
\text { C } & -2.1510 & -1.0445 & 0.1922
\end{array} \\
& \begin{array}{llll}
\text { C } & -2.7222 & -2.3062 & 0.4526
\end{array} \\
& \text { C } \quad-2.0550 \quad-3.2695 \quad 1.2485 \\
& \begin{array}{llll}
\text { C } & -0.7856 & -2.9443 & 1.7861
\end{array} \\
& \text { C } \quad-0.1875 \quad-1.6901 \quad 1.5490 \\
& \begin{array}{llll}
0 & 3.3143 & 2.8355 & -1.9198
\end{array} \\
& \begin{array}{llll}
\mathrm{N} & 2.3448 & 4.1305 & -4.1989
\end{array} \\
& \begin{array}{llll}
\text { C } & 1.2003 & 5.1357 & -2.2520
\end{array} \\
& \begin{array}{llll}
\text { C } & 0.4366 & 6.2536 & -2.9369
\end{array} \\
& \begin{array}{llll}
\text { C } & 1.1338 & 7.2979 & -3.6039
\end{array} \\
& \begin{array}{llll}
\text { C } & 0.4051 & 8.3672 & -4.1643
\end{array} \\
& \begin{array}{llll}
\text { C } & -1.0165 & 8.4288 & -4.0885
\end{array} \\
& \text { C } \quad-1.6904 \quad 7.3739 \quad-3.4055 \\
& \text { C } \quad-0.9830 \quad 6.2996 \quad-2.8313 \\
& \begin{array}{llll}
\text { Br } & 1.3677 & 9.8124 & -5.0594
\end{array} \\
& \text { Br }-3.6320 \quad 7.4346 \quad-3.2632 \\
& \begin{array}{llll}
0 & -1.7955 & 9.4454 & -4.6133
\end{array} \\
& \begin{array}{llll}
\text { C } & 2.6378 & 3.2947 & -5.2738
\end{array} \\
& \begin{array}{llll}
\mathrm{N} & 3.6859 & 3.6442 & -6.1470
\end{array} \\
& \begin{array}{llll}
0 & 1.9998 & 2.1857 & -5.4538
\end{array} \\
& \begin{array}{llll}
\text { C } & 4.3490 & 4.9414 & -6.1337
\end{array} \\
& \begin{array}{llll}
\text { C } & 3.8901 \quad 5.8636 & -7.2932
\end{array} \\
& \begin{array}{llll}
\text { C } & 4.0651 & 5.1204 & -8.6522
\end{array}
\end{aligned}
$$




\begin{tabular}{|c|c|c|c|}
\hline C & 3.3248 & 3.7468 & -8.6287 \\
\hline C & 3.7864 & 2.9101 & -7.407 \\
\hline N & 3.6088 & 5.9407 & -9.772 \\
\hline$C$ & 4.4006 & 6.2065 & -10.923 \\
\hline J & 3.6585 & 7.0276 & -11.805 \\
\hline C & 2.4039 & 7.3175 & -11.21 \\
\hline$C$ & 2.3676 & 6.6242 & -9.920 \\
\hline$C$ & 1.3188 & 8.0932 & -11.678 \\
\hline C & 0.1891 & 8.1738 & -10.821 \\
\hline C & 0.1508 & 7.5158 & -9.568 \\
\hline C & 1.2321 & 6.7316 & -9.087 \\
\hline ) & 5.5828 & 5.7672 & -11.1558 \\
\hline I & -1.1264 & 3.6434 & -1.894 \\
\hline I & -1.7695 & 2.3623 & -2.9553 \\
\hline I & 0.2936 & 2.3957 & -4.380 \\
\hline I & -0.4671 & 4.0111 & -4.2938 \\
\hline Y & 1.1901 & 1.7651 & 1.402 \\
\hline I & 1.5578 & 0.0096 & 1.41 \\
\hline [ & 2.0096 & -0.0486 & -1.011 \\
\hline 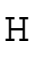 & 2.9299 & 1.3130 & -0.281 \\
\hline 1 & -0.9353 & 2.5334 & 0.200 \\
\hline 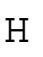 & -1.9864 & 1.2815 & -0.536 \\
\hline & -0.2554 & 0.6837 & -2.25 \\
\hline & -2 & -4 & \\
\hline
\end{tabular}




$$
\begin{aligned}
& \mathrm{H} \quad-0.2507 \quad-3.6737 \quad 2.4026 \\
& \begin{array}{llll}
\mathrm{H} & 0.7948 & -1.4871 & 1.9808
\end{array} \\
& \mathrm{H} \quad-2.7005 \quad-0.3383 \quad-0.4332 \\
& \mathrm{H} \quad-3.7019 \quad-2.5384 \quad 0.0234 \\
& \mathrm{H} \quad 0.6469 \quad 4.8455 \quad-1.3350 \\
& \mathrm{H} \quad 2.1876 \quad 5.5262 \quad-1.9259 \\
& \mathrm{H} \quad 2.9787 \quad 4.8863 \quad-4.0151 \\
& \mathrm{H} \quad 2.2211 \quad 7.2956 \quad-3.6830 \\
& \mathrm{H} \quad-1.5299 \quad 5.5068 \quad-2.3119 \\
& \begin{array}{llll}
\mathrm{H} & 2.8337 & 6.1832 & -7.1415
\end{array} \\
& \mathrm{H} \quad 4.5132 \quad 6.7835 \quad-7.2740 \\
& \mathrm{H} \quad 5.4481 \quad 4.7496 \quad-6.2077 \\
& \mathrm{H} \quad 4.1963 \quad 5.4727 \quad-5.1679 \\
& \mathrm{H} \quad 4.8524 \quad 2.5976 \quad-7.5278 \\
& \mathrm{H} \quad 3.1730 \quad 1.9830 \quad-7.3450 \\
& \mathrm{H} \quad 2.2218 \quad 3.8770 \quad-8.6072 \\
& \mathrm{H} \quad 3.5591 \quad 3.1684 \quad-9.5500 \\
& \mathrm{H} \quad 5.1625 \quad 4.9395 \quad-8.8304 \\
& \mathrm{H} \quad-1.1732 \quad 10.0350 \quad-5.0802 \\
& \mathrm{H} \quad 4.0041 \quad 7.3921-12.6610 \\
& \mathrm{H} \quad-0.6678 \quad 8.7675-11.1455 \\
& \mathrm{H} \quad-0.7353 \quad 7.6114 \quad-8.9379 \\
& \mathrm{H} \quad 1.1926 \quad 6.2449 \quad-8.1127 \\
& \mathrm{H} \quad 1.3488 \quad 8.6039-12.6388
\end{aligned}
$$




\section{$\left[{ }^{125}\right.$ I] CGRP Binding Assay}

Membrane Preparation. SK-N-MC cells endogenously expressing CGRP ${ }_{1}$ receptor are maintained in medium consisting of MEM with Earle's salts and Lglutamine (Gibco) supplemented with 10\% fetal bovine serum (Gibco). THE cells were rinsed twice with phosphate-buffered saline $(155 \mathrm{mM} \mathrm{NaCl}, 3.3 \mathrm{mM}$ $\mathrm{Na}_{2} \mathrm{HPO}_{4}, 1.1 \mathrm{mM} \mathrm{KH} \mathrm{PO}_{4}, \mathrm{pH} 7.4$ ), and incubated for $5-10$ min at $4^{\circ} \mathrm{C}$ in hypotonic lysis buffer consisting of $10 \mathrm{mM}$ Tris $(\mathrm{pH} \mathrm{7.4)}$ and $5 \mathrm{mM}$ EDTA. The cells were transferred from plates to polypropylene tubes $(16 \times 100 \mathrm{~mm})$ and homogenized using a polytron. Homogenates were centrifuged at $32,000 \times \mathrm{g}$ for $30 \mathrm{~min}$. The pellets were resuspended in cold hypotonic lysis buffer with $0.1 \%$ mammalian protease inhibitor cocktail (Sigma) and assayed for protein concentration. The SK-N-MC homogenate was then aliquoted and stored at $80^{\circ} \mathrm{C}$ until needed.

Assay. $\left[{ }^{125} \mathrm{l}\right]$-CGRP (Amersham Biosciences) (final concentration $15 \mathrm{pM}$ ), different concentrations of the compounds, and membrane preparation, all suspended in assay buffer (final concentration: $50 \mathrm{mM}$ Tris-Cl pH 7.5, $5 \mathrm{mM}$ $\mathrm{MgCl}_{2}, 0.0005 \%$ Triton $\mathrm{X}-100$ ) were incubated at room temperature for 2 hours. The reaction was terminated by the addition of excess cold wash buffer $(20 \mathrm{mM}$ Tris-Cl $\mathrm{pH} 7.5,0.1 \% \mathrm{BSA}$ ) immediately followed by filtration over glass fiber filters (Whatman GF/B) previously soaked in $0.5 \%$ PEI. Non-specific binding was defined with $1 \mu \mathrm{M}$ beta-CGRP. Protein bound radioactivity was determined using 
a gamma or scintillation counter. The $\mathrm{IC}_{50}$ was defined as the concentration of a compound of invention required to displace $50 \%$ of radioligand binding. 